$$
\begin{aligned}
& \text { Accelerator Department } \\
& \text { BROOKHAVEN NATIONAL LABORATORY } \\
& \text { Associated Universities, Inc. } \\
& \text { Upton, New York. } \\
& \text { AGS DIVISION TECHNICAI NOTE } \\
& \text { No. } 62 \\
& \text { L.E. Repeta and V.J. Buchanan } \\
& \text { Ju1y 8, 1969 } \\
& \text { ELECTROSTATIC INELECTOR }
\end{aligned}
$$

\title{
Introduction
}

Multiturn injection has been used at the AGS since August 1964 and has been accomplished by using an electrostatic inflector and associate equipment.

The proton beam leaves the linear accelerator on an optic axis that lies on the median plane of the AGS ring. The beam moves along the axis of the beam transport, which is approximately $4-i n$. outside a tangent line to the AGS. As the beam moves along this flight path, it is deflected toward the ring. The final tangency of the linac beam to the AGS ring is accomplished by the electrostatic inflector.

\section{Mechanical Design}

The inflector is located at the edge of the usable machine aperture at the $10 \mathrm{ft}$ straight section " $\mathrm{L}-20$ ". The major components of the inflector are shown in a cross sectional view in Fig. 1. The main assembly drawing is D07-M-5103-5, and anyone interested in greater detail should refer to. this drawing.

A simplified plan view, with cover removed, is shown in Fig. 2. The sub-base is accurately surveyed in position relative to the line joining the magnet sockets $\left(S_{0}\right)$ of the "L-20" and "A-1" AGS main ring magnets. The inflector sub-assembly is accurately positioned, relative to the sub-base, 


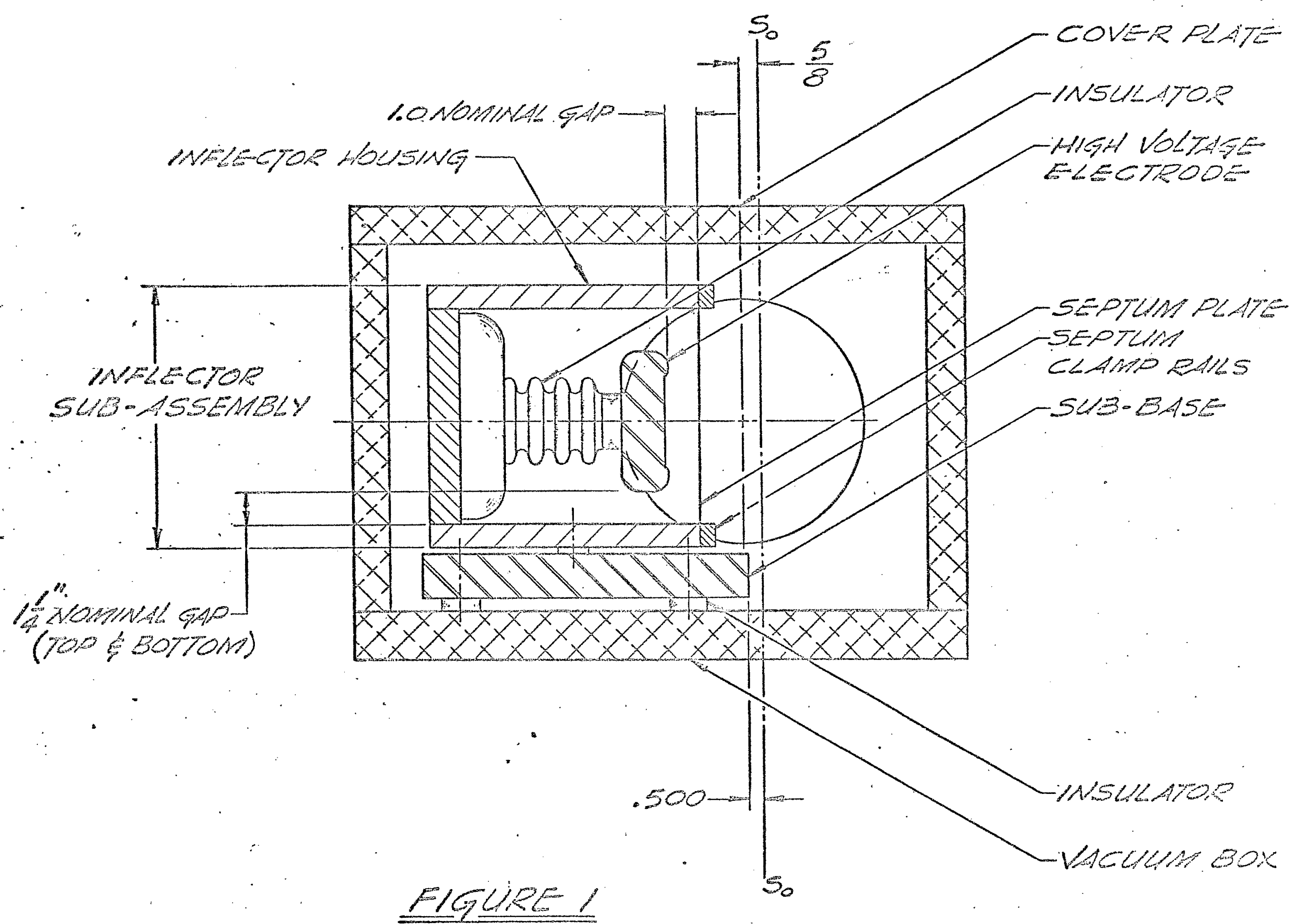


through the use of three gage blocks as noted in the figure. The use of these gage blocks facilitates accurate location without survey and insures accurate repositioning of the inflector subassembly, after it has been removed for maintenance, with minimum effort and time.

The high voltage electrode is 60-in. Iong and is made from 606I-T6 aluminum alloy highly polished all over. The electrode front face shape, shown in Fig. 3 was optimized by making equi-potential plots on high resistance paper of ten times size cross sections. The normal running voltage is a negative $45 \mathrm{kV}$.

Shown in Fig. 4 is a two piece copper shield block that is fastened. to, and insulated from, the inflector sub-assembly. In addition, each of the two component pieces are insulated from each other. The function of this block is to- -1 ) act as a collimator for the linac beam, and 2) to provide a protective shield for the outside face of the thin $(0.015)$ septum plate from the orbiting beam. Ceramic beaded, copper signal wire has been run from each piece to a vacuum feed thru located on the front face of the vacuum box; co-ax cable then runs to the AGS Main Contro1 Room. This enables close monitoring for study and evaluation of the signal generated by the entering linac beam "wiping off" on entrance through the opening of the copper block, and the signal generated by the circulating beam "wiping off" on the outside edge of the block as it passes the outside of the inflector.

After several weeks of operation it was found that a thermal breakdown

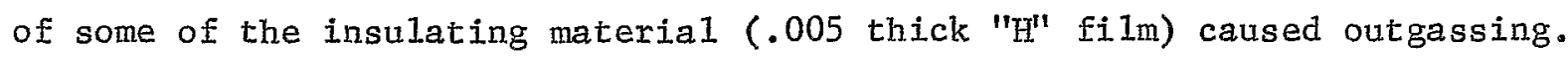
This resulted in a serious arcing problem that intermittently tripped the inflector off. The two piece copper shield block was removed and replaced by a one piece shield block. A new split block has been designed and is now ready for installation. 
The upstream inflector viewing flag and its basic dimensions are shown in Fig. 5. The flag can be remotely positioned to either of the two working positions denoted, or withdrawn within the shadow of the vacuum pipe by activating a 24 volt d.c. linear actuator drive motor from the Main Control Room. A potentiometer readout system, accurately calibrated by the AGS Target Group, enables the machine operator to position the flag in the desired position. The flag is viewed in the Main Control Room via closed circuit television. Operating position $\#_{1}$ is useful when setting up or for studies purposes, but not satisfactory for efficient machine operation because the obstruction presented by the 1/8-in. thick quartz plate "stops" most of the $50 \mathrm{MeV}$ beam. Switching to position $\left.\right|^{2}$, the machine operator can center the air gap between the two quartz pieces to the injected beam centerline. The obstruction of the beam due to the flag has been removed and this position also enables the operator to monitor any horizontal movement of the entering beam during norma 1 machine running. Introduction to the Calculations

A computer analysis was made by Dr.A.W. Maschke to determine the initial parameters to be used. A 22 milliradian entrance angle, directed toward the center of the AGS machine, resulted in an offset from the computer coordinate line to the injection line of 2.904 inches (see Fig. 6). The high voltage electrode was to be 60-in. 1ong and an approach angle of 4 milliradians directed away from the center of the AGS, was to be used. The entrance and approach angles were to be distributed equally over the electrode length. Geometric Position and Attitude

Sign convention:

Positive $(t)$ denotes increasing radius and, Negative ( $(-)$ denotes decreasing radius (toward the center of the AGS ring). 


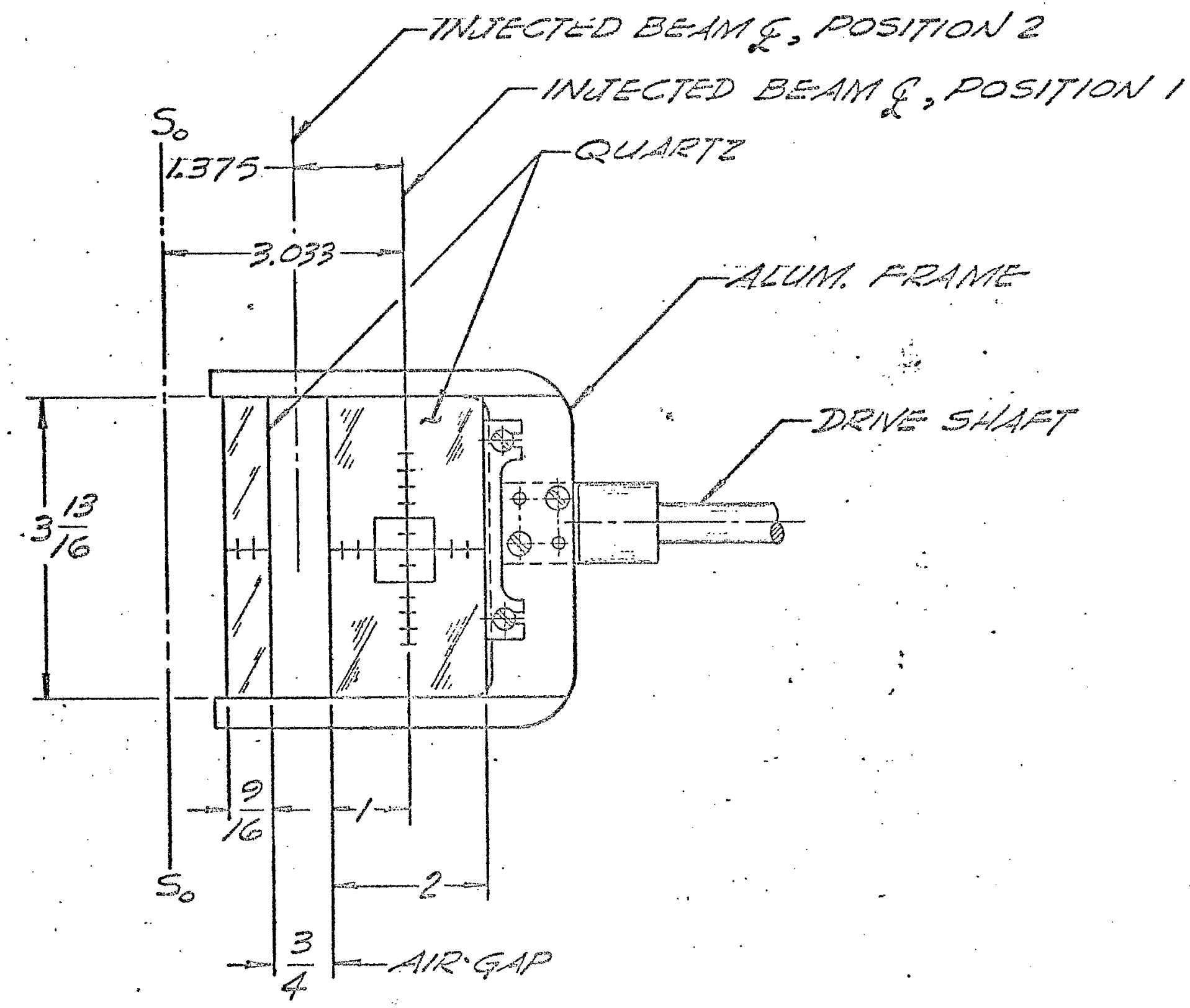

UPSTREAM INFECYOR ELAG (DOTM ETI-3) VIEW LOOKNG DOWN STREANT

FIGLIRES 
Refer to Fig. 6 .

From the beam program coordinate line to the line joining the magnet sockets $\left(s_{0}\right)$ as taken from drawing D05-412-2.

$$
\mathrm{y}_{1}=0.035
$$

From the beam program coordinate line to an extension of the vacuum chamber centerline in " $\mathrm{L}-20$ " (computer coordinate 1ine)

$$
y_{2}=12^{\prime \prime}\left(\tan 0^{\circ} 36^{\prime}\right)=12(0.01047)=
$$

Offset from the computer coordinate line to the injection line as taken from the computer sheet

Offset 6-in. downstream at 22 milliradians

$$
y_{3}=-6.000(0.022)=
$$

$\frac{y_{3}=0.132}{2.933}$

Centerline of a 1/2-in. diameter beam will enter the inflector 3/8-in. from the inside face of the septum plate

Distance from the socket line to the inside face of the septum at the upstream end of the inflector electrode

The electrode gap will go upstream for 30-in. at 22 miliradians

$$
-30^{\prime \prime}(0.022)=
$$

The electrode gap will then continue upstream for $30-$ in. at 4 milliradians

$$
+30^{\prime \prime}(0.004)=
$$

The centerline of the beam will leave the gap $1 / 8-i n$. closer to the septum plate, graze the septum plate and exit

Distance from the socket line to the inside face of the septum at the downstream end of the inflector electrode

Refer to Fig. 7.

The septum sheet angle:

$$
22 \mathrm{mR}+4 \mathrm{mR}=26 \mathrm{mR} ; \quad 26 \mathrm{mR} / 2=13 \mathrm{mR}
$$




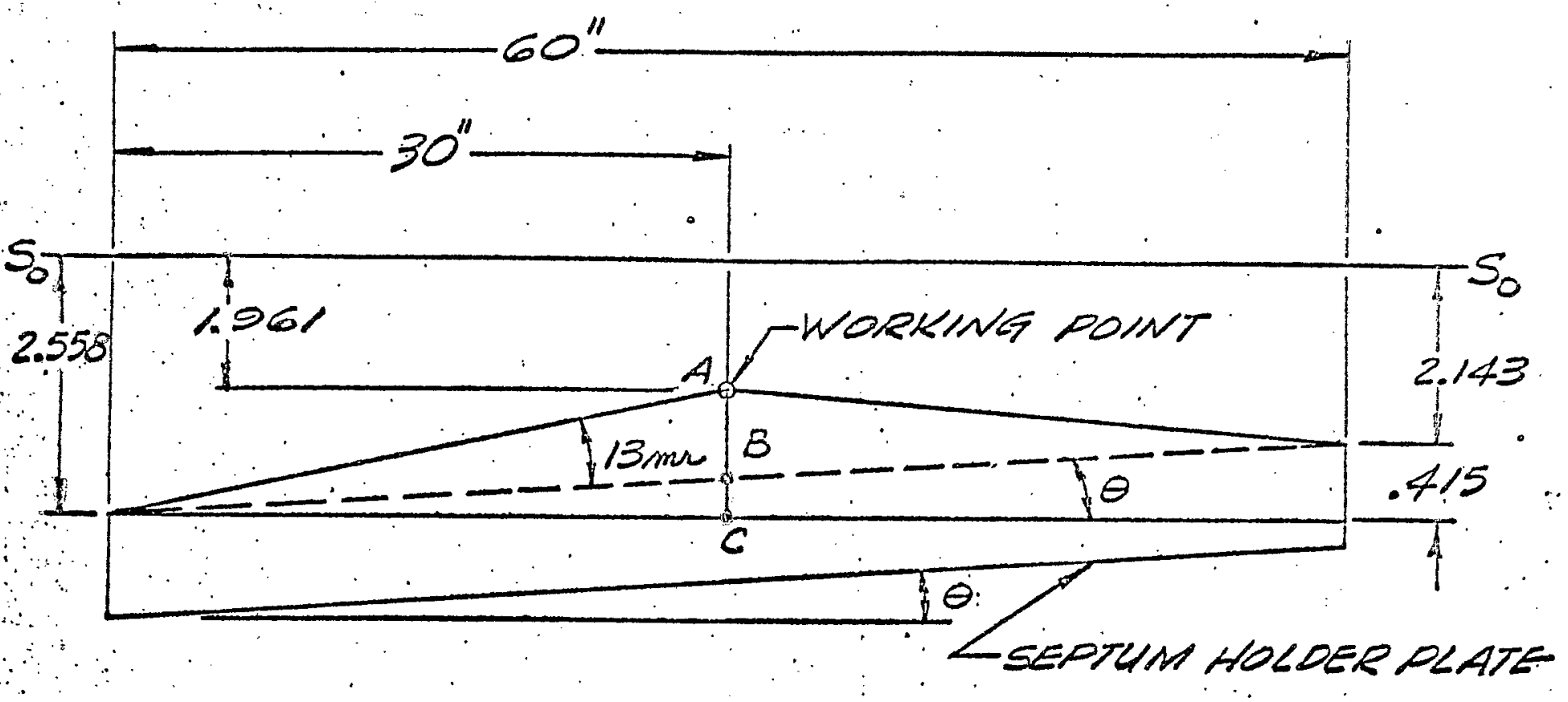

\section{FIGURE 7}

THE CALCULATION OF THE ANGLE AT THE BACK OF THE SEPTUM

HOLDER PLATES $(\theta$ in figure 7$)$ 。

(1) $\begin{array}{r}2.558 \\ -2.143 \\ \hline 0.415\end{array}$

(2) $\operatorname{Tan} \theta=\frac{.415}{00}=0.006916 \approx 0.007$

$\therefore$ Let $\theta=7$ milliradians

Socket line to the inside of the septum at the upstream end of the electrode

The septum goes upstream for $30^{\prime \prime}$ at $13 \mathrm{mr}$

$$
-30(0.013)=
$$

Distance $\overline{\mathrm{BC}}$ (figure 7)

$$
\frac{.415}{60}=\frac{B C}{30} ; \overline{B C}=\frac{.45 \quad(30)}{60}=
$$

Distance from the socket Iine to the working point in firgure 7

The septum sheet angle

$+13 \mathrm{mr}$

The angle at the back of the septum holder plates

$\frac{+7 \mathrm{mr}}{+20 \mathrm{mr}}$ 
GAGE BLOCK CALCULATIONS (refer to figure 2)

The upstream gage point will be $2.875^{\prime \prime}$ at $20 \mathrm{mr}$ upstream of the end of the electrode

$$
2.875(0.020)=
$$

From the socket line to the inside face

of the septum at the upstream end

From the socket Iine to the edge of the s:ub-base

The gage dimension (upstream end) from the edge of the sub-base

The septum sheet angle

$-13 \mathrm{mr}$

The angle at the back of the septum holder plates

$$
\frac{+7 m r}{-6 m r}
$$

The downstream gage point will ve $2.125^{\prime \prime}$ at 6 mr downstream from the end of the electrode

$$
2.125(0.006)=0.01275 \approx
$$

From the socket line to the inside face of the septum at the downstream end

From the socket 1 ine to the edge of the sub-base $-0.500$

The gage dimension" (downstream end) from the edge of the sub-base 
COPPER SHEILD BLOCK LOCATION

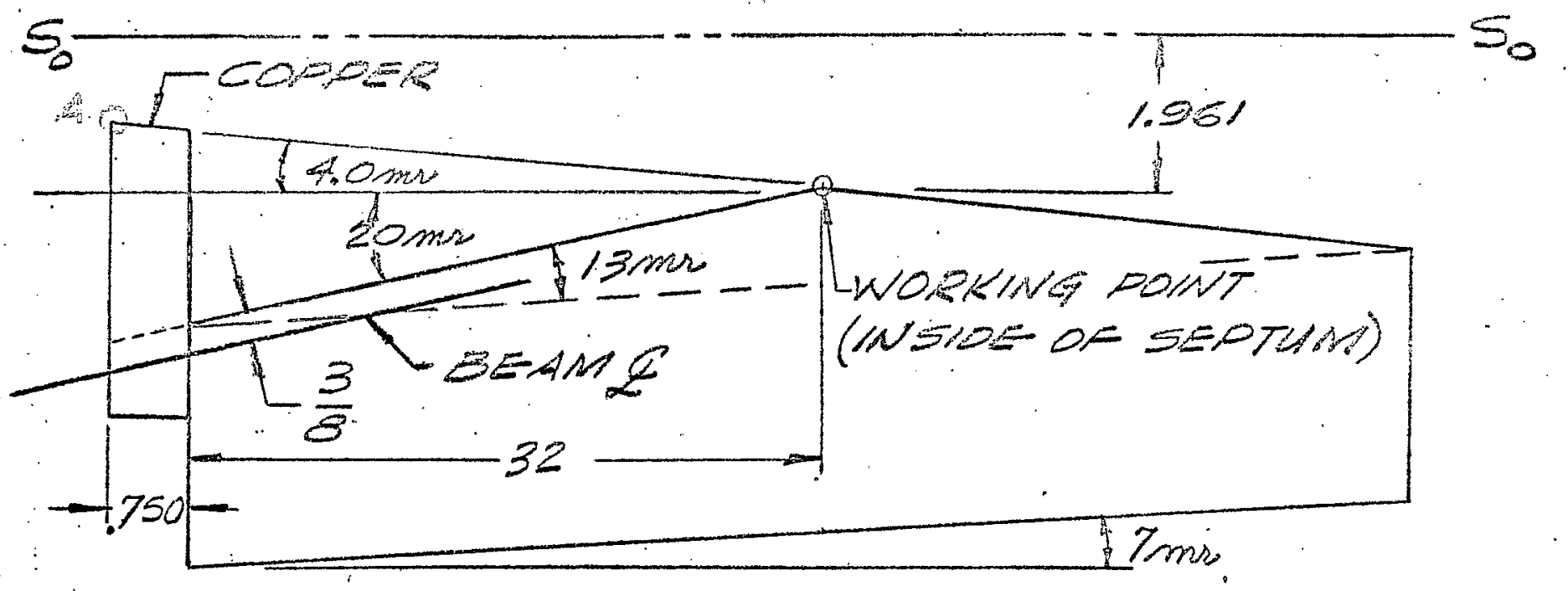

FIGURE 8

From the socket Iine to the working point

With a 4no approach angle at $32.750^{\prime \prime}$

$$
-32.750(0.004)=
$$

$-0.131$

1.830

The septum thickness

$-0.015$

From the socket line to the leading edge of the copper block, Point "A"

From the socket Iine to the edge of the sub-base

$-0.500$

From the edge of the sub-base to the edge of the copper shield block 


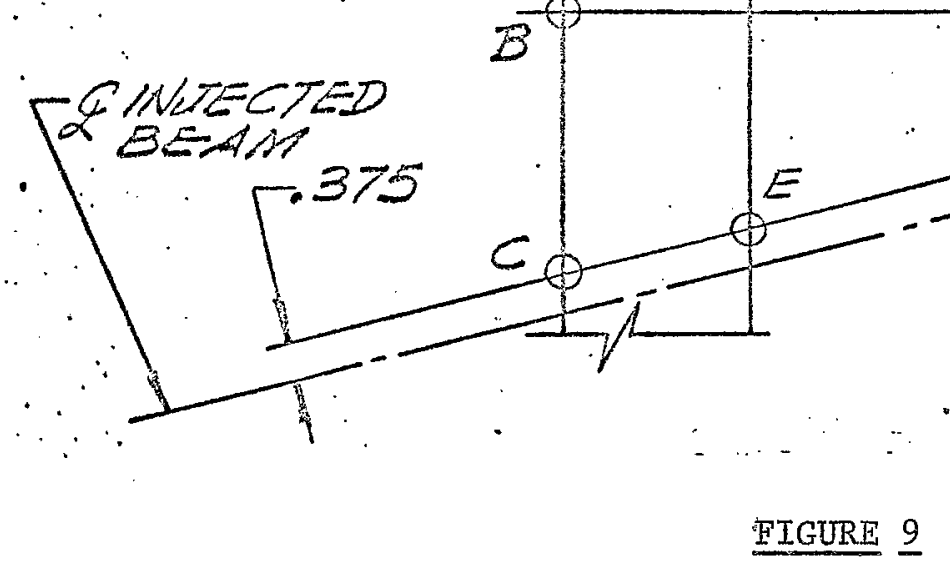

BLOCK SLOT POSITION

The vertical distance $\overline{\mathrm{AB}}$

$$
32.750(0.004)=
$$

The vertical distance $\overline{\mathrm{BC}}$

$$
32.750(0.020)=
$$

The leading edge of the copper to the inside face of the septum plate

The septum thickness $+0.015$

From the edge of the septum to the beam centerline

From the leading edge of the copper shield block to the slot centerline in the block

BLOCK LEADING EDGE TAPER

The vertical distance $\overline{\mathrm{DE}}$

$$
\begin{aligned}
& 32.000(0.024)= \\
& 0.786 \\
& -0.768 \\
& \hline 0.018
\end{aligned}
$$




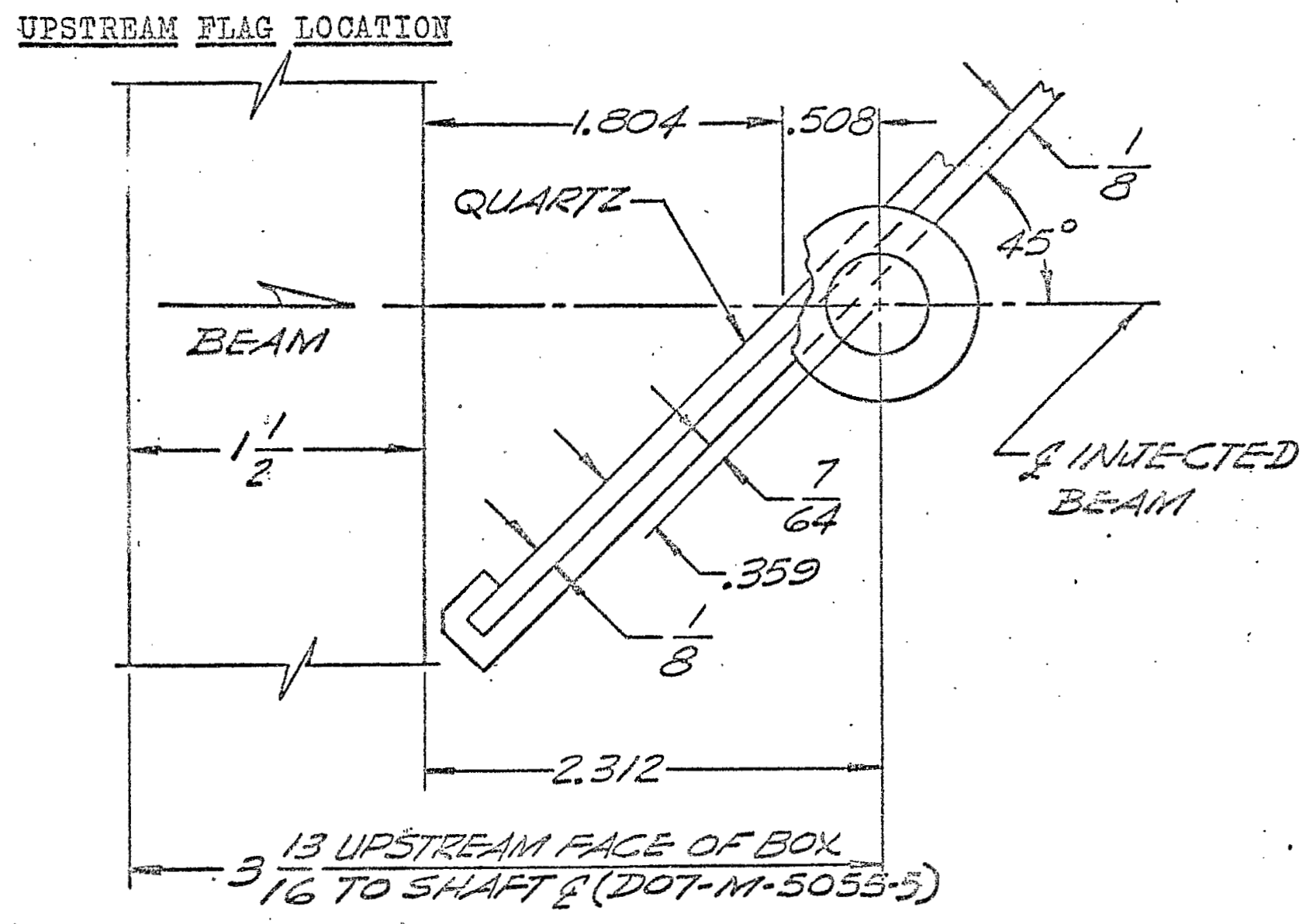

FIGURE 10

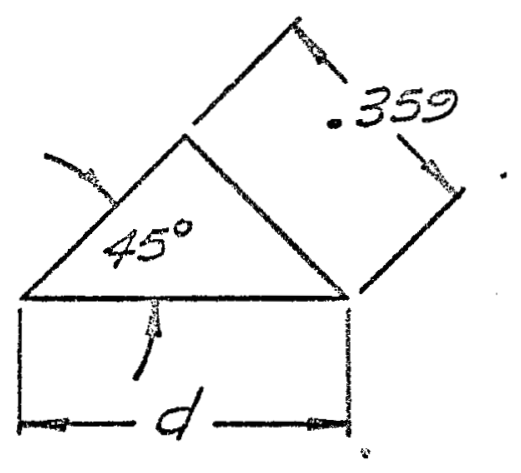

(1) $\sin 45^{\circ}=\frac{0.359}{\mathrm{~d}}$

$d=\frac{0.359}{0.707}=0.5077 \approx 0.508$

(2) $\begin{array}{r}2.312 \\ -0.508 \\ \hline 1.804\end{array}$

From the socket line to the injected beam centerline from figure 6

From the inside face of the vacuum box to the beam centerline on the quartz 1.804

From the inside face of the vacuum box to $\frac{-0.375}{1.429}$
the datum line in figure 6

The injected beam goes upstream $1.429^{\prime \prime}$ at $22 \mathrm{mr}$

$$
1.429(0.022)=\quad \frac{-0.032}{3.033}
$$




\section{ALTERNATE POSTTIONS}

There are two secondary, alternate, positions that the inflector could occupy in addition to the primary position that has been described. The first auxilliary position, or middle position, represents a +0.220 outward shift of the working point. The second shift, outer position, is equal to a +0.440 displacement of the working point from the primary position. When the inflector sub-assembly is moved outward the approach angle changes by 2 milliradians per inch of displacement. In addition then, to the outward shift, a clockwise rotation of the inflector subassembly is also required. To accomplish these changes of position; 1) additional gage blocks are required, 2) the copper shield block location relative to the socket Iine and sub-base changes, 3) the flag position changes relative to the socket line. Assuming that the 22 milliradian entrance angle remains the same, the offset to the centerline of the injecced bean (figure 6) must also change. As a point of caution, if one or the other of these alternate positions were to be used and evaluated, an outward shift of the entire beam transport from the Iinac to the inflector may be required, else the beam might scrape the side of the vacuum chamber.

ALTERNATE WORKING POINT POSITIONS

Distance from the socket Iine to the working point, see figure 7

Move inflector sub-assembly out $0.220^{\prime \prime}$ $+0.220$

Distance from the socket line to the new working point (middle position) 
Distance from the socket line to the working point, see figure 7

Move inflector sub-assembly out $0.440^{n}$

Distance from the socket line to the new working point (outer position)

\section{GAGE BLOCK CAICULATIONS}

Middle position:

The gage dimension (upstream end) from the edge of the sub-base, see page 12

Move inflector out $0.220^{\prime \prime}$

Since the angle changes $2 \mathrm{mr} /$ inch

$$
\frac{2}{1}=\frac{\alpha}{.22} ; \alpha=0.44 \mathrm{mr}
$$

Upstream gage point is $32,875^{\prime \prime}$ upstream of the working point

Rotate the inflector $0.44 \mathrm{mr}$ clockwise about the working point

$$
32.875(0.000444)=0.0145
$$

$-0.014$

Gage dimension (upstream end) from the edge of the sub-base

The gage dimension (downstream end) from

Move inflector out $0.220^{\prime \prime}$

$+0.220$

Downstream gage point is $32,125^{\prime \prime}$ downstream of the working point

Rotate the inflector $0.44 \mathrm{mr}$ clockwise about the working point

$$
32.125(0.00044)=0.0141
$$

$+0.014$

Gage dimension (downstream end) from the edge of the sub-base 


\section{GAGE BLOCK CALCULATIONS}

\section{Outer position:}

The gage dimension (upstream end) from the edge of the sub-base, see page 12

Move the inflector out $0.440^{\prime \prime}$

$+0.440$

Since the angle changes $2 \mathrm{mr} /$ inch

$$
\frac{2}{I}=\frac{\beta}{.44} ; \beta=0.88 \mathrm{~m} r
$$

Upstream gage point is $32.875^{\prime \prime}$ upstream of the working point

Rotate the inflector $0.88 \mathrm{mr}$ clockwise about the working point

$$
32.875(0.00088)=0.028
$$

Gage dimension (upstream end) from the edge of the sub-base

$$
2.527=\mathrm{U}_{1 \mathrm{~A}}
$$

The gage dimension (downstream end) from the edge of the sub-base, see page 12

$$
1.656
$$

Move the inflector out $0.440^{\prime \prime}$

$+0.440$

Downstream gage point is $32.125^{\prime \prime}$ down-

stream of the working point

Rotate the inflector $0.88 \mathrm{mr}$ clockwise about the working point

$$
32.125(0.00088)=0.028
$$

$+0.028$

Gage dimension (downstream end from

the edge of the sub-base

$$
2.124=\mathrm{D}_{1 \mathrm{~A}}
$$


COPPER SHIELD BLOCK LOCATION

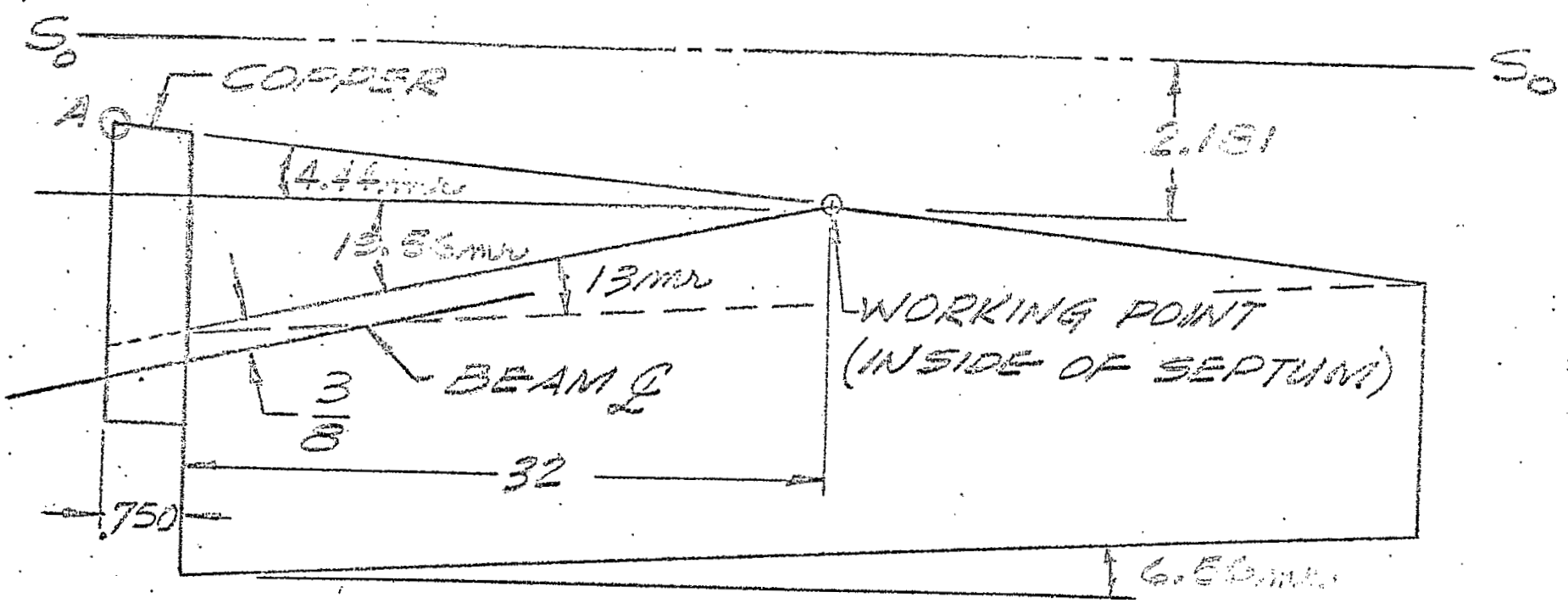

FIGURE 11

MTDDLE POSITION

From the socket line to the working point

1.961

Move the inflector out $0.220^{\prime \prime}$

$+0.220$

Distance from the socket Iine to the new working point

The approach angIe increases by $0.44 \mathrm{mr}$

With a $4.44 \mathrm{mr}$ approach angle at $32.750^{\prime \prime}$

$$
32.750(0.00444)=0.145
$$

The septum thickness

$$
\frac{+0.015}{0.160}
$$

Socket Iine to the edge of the copper block, point "A" in figure 11

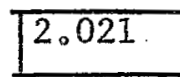

Socket Iine to the edge of the sub-base

$$
-0.500
$$

Edge of the sub-base to the edge of the copper block 
COPPER SHTELD BLOCK IOCATION

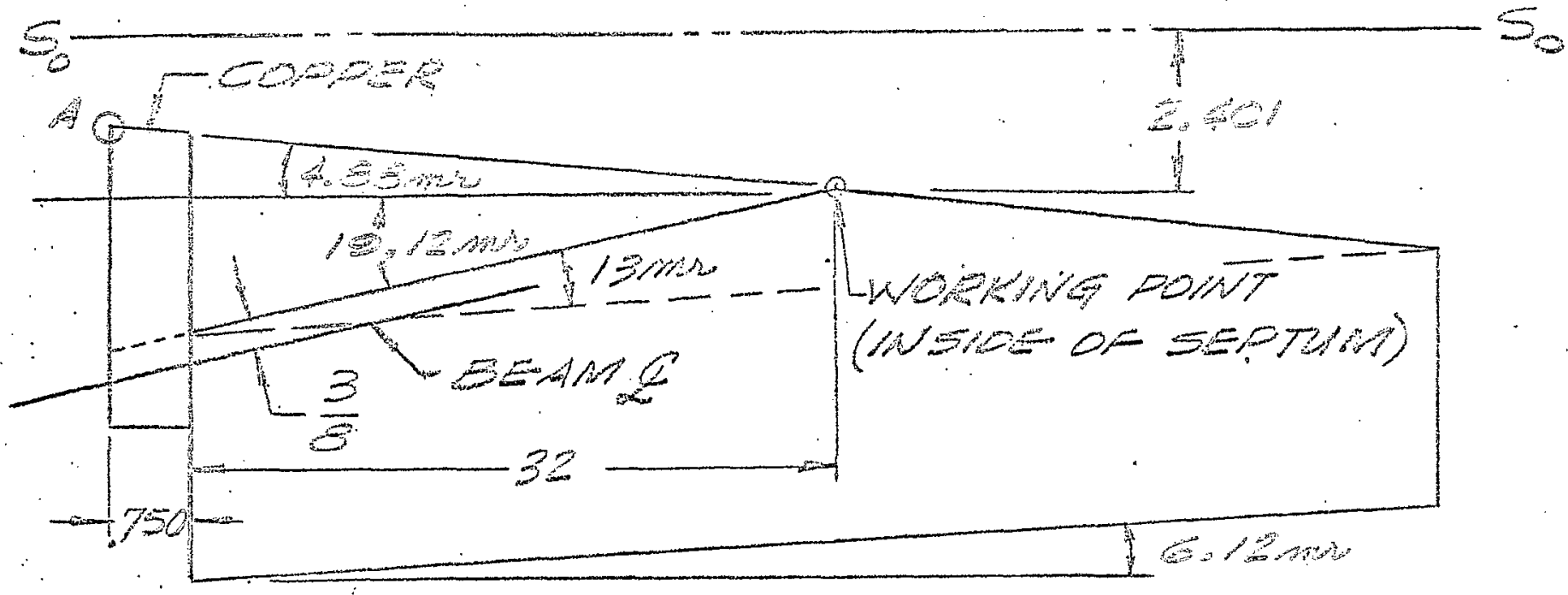

FIGURE 12

OUTER POSITION

From the socket Iine to the working point

Move the inflector out $0.44^{\prime \prime}$

$+0.440$

Distance from the socket line to the new working point

The approach angle increases by $0.88 \mathrm{mr}$

With a 4.88mr approach angle at $32.750^{\prime \prime}$

$$
32.750(0.00488)=0.160
$$

The septum thickness

$$
+0.015
$$

$$
0.175
$$

Socket Iine to the edge of the copper

block, point "A" in figure 12

Socket line to the edge of the sub-base

Edge of the sub-base to the edge of the copper block 
OEFSET TO THE INJECTION IINE

Middle position:

Upstream gage block dimensions, seè page 17

Socket Iine to the edge of the sub-base

$+0.500$

2.821

Move downstream $2.875^{\text {It }}$ at $19.56 \mathrm{mr}$

$-0.056$

Socket Iine to the inside face of the septum at the upstream end of the electrode

CenterIine of the $1 / 2^{\prime \prime}$ dia obeam will enter the inflector $3 / 8^{\prime \prime}$ from the inside of the septum

Offset $6^{\prime \prime}$ downstream at $22 \mathrm{mr}$

$$
\begin{aligned}
& 6.000(0.022)= \\
& y_{1} \text { from page } 9=0.035 \\
& y_{2} \text { from page } \dot{9}=\frac{+0.126}{0.161}
\end{aligned}
$$

Offset to the injection Iine (middle position)

3.111

Outer position:

Upstream gage block dimension, see page 18

Socket Iine to the edge of the sub-base

$\frac{+0.500}{3.027}$

Move downstream $2.875^{\prime \prime}$ at 19.12mr

$-0.055$

Socket Iine to the inside face of the septum at the upstream end of the electrode

Centerline of the $I / 2^{\prime \prime}$ dia. beam will enter the inflector $3 / 8^{\prime \prime}$ from the inside of the septum

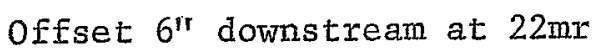
$+0.132$

$y_{1}+y_{2}=0.161$

offset to the injection Iine (outside position) 
ALTERNATE FLAG LOCATIONS

Middle position:

Offset to the injection line, see page 21

$y_{1}+y_{2}=0.161$ from page 9

$+0.161$

3.272

Move $1.429^{\prime \prime}$ upstream at $22 \mathrm{mr}$, see page 15

$$
1.429(0.022)=
$$

From the socket Iine to the flag centerline

Outer position:

Offset to the injection Iine, see page 21

$y_{1}+y_{2}=0.161$ from page 9

$+0.161$

3.479

Move $I_{0} 429^{\prime \prime}$ upstream at $22 \mathrm{mr}$, see page 15 .

$$
1.429(0.022)=
$$

$-0,032$

From the socket Iine to the flag centerline 
SUMMARY OF DATA

\begin{tabular}{|c|c|c|c|c|c|}
\hline Location & $\begin{array}{l}\text { Socket Iine to the } \\
\text { Working Point }\end{array}$ & $\begin{array}{l}\text { Gage Block } \\
\text { Dimensions }\end{array}$ & $\begin{array}{l}\text { Gage Block } \\
\text { Symbols }\end{array}$ & $\begin{array}{l}\text { Socket Iine to edge } \\
\text { of the copper block }\end{array}$ & $\begin{array}{l}\text { Socket line to the } \\
\text { Quartz Flag }\end{array}$ \\
\hline Primary & 1.961 & $\begin{array}{l}2.115 \\
1.656\end{array}$ & $\begin{array}{r}\mathrm{U}_{3} \\
\mathrm{D}_{3} \\
\end{array}$ & 1.815 & 3.033 \\
\hline Middle & 2.181 & $\begin{array}{l}2.321 \\
1.890\end{array}$ & $\begin{array}{l}\mathrm{U}_{2} \\
\mathrm{D}_{2}\end{array}$ & 2.021 & 3.240 \\
\hline Outer & 2.401 & $\begin{array}{l}2.527 \\
2.124\end{array}$ & $\begin{array}{l}\mathrm{U}_{1 \mathrm{~A}} \\
\mathrm{D}_{1 \mathrm{~A}}\end{array}$ & 2.226 & 3.447 \\
\hline
\end{tabular}

* "U" denotes upstream and "D" denotes downstream

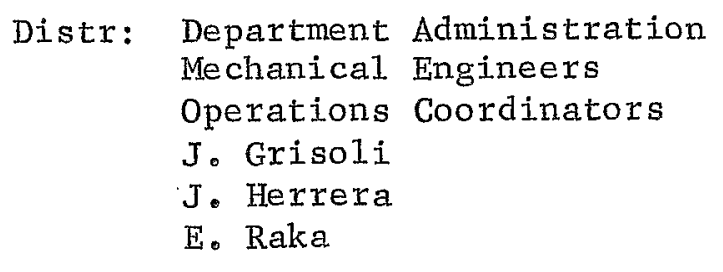

